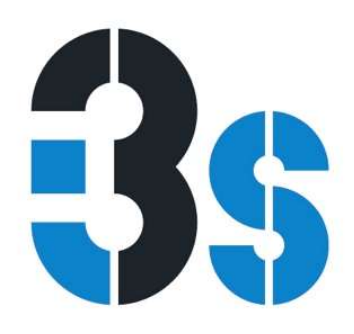

\title{
Ketamine induction of p53- dependent apoptosis and oxidative stress in zebrafish (Danio rerio) embryos
}

\author{
Luís M. Félix, Ana M. Vidal, Cindy Serafim, Ana \\ M. Valentim, Luís M. Antunes, Sandra M. \\ Monteiro, Manuela Matos, Ana M. Coimbra
}

Originally published in Félix, L. M., Vidal, A. M., Serafim, C., Valentim, A. M., Antunes, L. M., Monteiro, S. M., Matos Manuela, Coimbra, A. M. (2018). Ketamine induction of p53-dependent apoptosis and oxidative stress in zebrafish (Danio rerio) embryos. Chemosphere, 201, 730-739 (doi: 10.1016/j.chemosphere.2018.03.049).

\begin{abstract}
Ketamine is a widely used pharmaceutical that has been detected in waters worldwide. Zebrafish embryos were used in this study to investigate the oxidative stress and apoptotic signals following a 24 -hour exposure to different ketamine concentrations ( $0,50,70$ and $90 \mathrm{mg} \mathrm{L}$ ). Early blastula embryos ( 2 hours post fertilization- hpf) were exposed for 24 hours and analysed at 8 and 26 hpf. Reactive oxygen species and apoptotic cells were identified in vivo, at $26 \mathrm{hpf}$. Enzymatic activities (superoxide dismutase (SOD), catalase (CAT), glutathione peroxidase (GPX), lactate dehydrogenase $(\mathrm{LDH})$ and acetylcholinesterase (AChE)), glutathione levels (oxidized (GSSG) and reduced (GSH)), oxidative damage (lipid peroxidation (LPO) and protein carbonyls (CO)) as well as oxidative stress (gclc, gstp1, sod1 and cat), apoptosis (casp3a, casp6, casp8, casp9, aifm1 and tp53) and cell proliferation (pcna) related-genes were evaluated at 8 and 26 hours post fertilization (hpf). The activity of caspase ( 3 and 9 ) was also determined at both time-points by colorimetric methods. Superoxide dismutase (SOD), catalase (CAT), gluthathione levels (GSSG), caspase- 9 and reactive oxygen species (ROS) were shown to be affected by ketamine exposure while in vivo analysis showed no difference in ROS. A significant up-regulation of superoxide dismutase (sod1) and catalase (cat) genes expression was also perceived. Ketamine-induced apoptosis was observed in vivo and confirmed by the apoptotic-related genes up-regulation. The overall results suggest that ketamine induced oxidative stress and apoptosis through the involvement of p53-dependent pathways in zebrafish embryos which could be important for the evaluation of the overall risk of ketamine in aquatic environments.
\end{abstract}

Keywords: Ketamine; gene expression; apoptosis; oxidative stress; zebrafish 


\section{INTRODUCTION}

Over the last years, numerous studies have reported a rise in water contamination by pharmaceuticals (Fent et al., 2006). These compounds have been detected in wastewaters and surface waters around Europe (Zuccato and Castiglioni, 2009; Petrie et al., 2015). Because of that, they have been considered emerging aquatic pollutants (Zuccato and Castiglioni, 2009; Rodayan et al., 2016). Although being present at low concentration levels, they constitute a major risk to aquatic life and to human health (Pomati et al., 2006; Petrie et al., 2015; Rodayan et al., 2016), due to continuous discharges and their resistance to degradation (Santos et al., 2010; Sui et al., 2015). Moreover, most of these compounds are currently not subject to control under European Legislation (Mounteney et al., 2016).

Ketamine, a dissociative glutamatergic hallucinogen widely used in developing countries for medical and non-medical purposes (Jansen, 2000; Lin et al., 2014a). Ketamine has been classified as an emergent contaminant in some countries as it has been detected in both domestic (contemplating the abuse and diversion use of ketamine) and hospital waste effluents sewerage systems (Lin et al., 2010; Jiang et al., 2014; Lin et al., 2014a; Castiglioni et al., 2015). The persistency of ketamine in the environment and the formation of more toxic byproducts (Lin et al., 2014b) could represent an ecological risk that can result in long-term adverse effects as observed after exposure to different chemicals due to, among others, the dysregulation of developmental processes (Lupien et al., 2009; Santos et al., 2010; Perera and Herbstman, 2011; Grandjean et al., 2015).

Zebrafish (Danio rerio) is a well-established alternative laboratory model organism that has been widely used in the ecotoxicology field due to several advantageous characteristics over other animal models (Seok et al., 2008; Dai et al., 2014). Particularly, due to its high sensitivity to environmental stress (Zhu et al., 2015), the early life stages of zebrafish have been extensively used for environmental risk assessment (Scholz et al., 2008). There are some toxicity studies focused on the influence of ketamine short exposure during the early organogenesis development of zebrafish (e.g., lethality, oxidative stress, apoptosis and behavioral deficits (Felix et al., 2014; Felix et al., 2016a; Felix et al., 2016b; Felix et al., 2017a; Felix et al., 2017c). Additionally, other embryo-larval developmental toxicity assays have been conducted during this development vulnerable window of exposure with long exposure periods (at least for $24 \mathrm{~h}$ ) in zebrafish (Felix et al., 2017b; Robinson et al., 2017) and also in other aquatic models, such as Oryzias latipes and Xenopus laevis embryos (Liao et al., 2015; Guo et al., 2016), showing similar outcomes through the involvement of oxidative stress and apoptotic pathways (Liao et al., 2017). Notwithstanding these studies, little is known on the mechanism of ketamine teratogenicity in zebrafish early stages. Therefore, the aim of this work was to evaluate the impact of a 24-hour exposure to ketamine concentrations high enough to disturb zebrafish developmental processes, focusing on oxidative stress and apoptosis biomarkers, in order to elucidate the toxicity mechanism(s) (Felix et al., 2017b). Overall, this approach is commonly used for chemical risk assessment (Arnold et al., 2017). 


\section{Materials and Methods}

\section{Ethical statement}

This study was carried out in strict accordance with the recommendations for care and use of laboratory animals of the EU directive (2010/63/EU) and National (Decreto-Lei 113/2013) legislation for animal experimentation and welfare. The experiments performed in this work were under project license approval by the Portuguese competent authority, Direcção Geral de Alimentação e Veterinária (DGAV, Lisboa, Portugal). All efforts were made to minimize suffering of adult zebrafish.

Reagents

Ketamine (ketamine hydrochloride, Imalgene1000, $100 \mathrm{mg} \mathrm{mL}-1$ ) was obtained from Merial Portuguesa-Saúde Animal Lda (Rio de Mouro, Portugal). All solutions were freshly made with embryo water ( $28 \pm 0.5^{\circ} \mathrm{C}, 200 \mathrm{mg} \mathrm{L}-1$ Instant Ocean Salt and $100 \mathrm{mg} \mathrm{L}-1$ sodium bicarbonate; UV sterilized) prepared from City of Vila Real filtered-tap water. Instant Ocean Salt was obtained from Aquarium Systems Inc. (Sarrebourg, France). Caspase substrates were purchased from Enzo Life Sciences International Inc. (Farmingdale, New York, USA). p-nitroaniline (pNA) was acquired from Santa Cruz Biotechnology (Santa Cruz, California, USA). Oligo primers were purchased from Stabvida Lda. (St. Antonio de Oeiras, Portugal). All other chemicals were of analytical grade and obtained from SigmaAldrich (Steinheim, Germany).

\section{Selection of exposure concentrations}

Ketamine concentrations of 50,70 and $90 \mathrm{mg} \mathrm{L}-1$ ( $0.21,0.29$ and $0.38 \mathrm{mM}$, respectively) were chosen based on the previous determined $24 \mathrm{~h}-\mathrm{LC} 50$ ( $94.4 \mathrm{mg} \mathrm{L}-1$ ) (Felix et al., 2017c) established according to OECD standard protocol (OECD 236) with minor modifications.

\section{Experimental design}

Adult zebrafish (Danio rerio) were maintained as previously described (Felix et al., 2014). Briefly, wildtype (AB strain) zebrafish embryos, were maintained at the University of Trás-os-Montes and Alto Douro (Vila Real, Portugal) in an open water system supplied with aerated, dechlorinated, charcoalfiltered and UV-sterilized City of Vila Real tap water $(\mathrm{pH} 7.3-7.5)$ at $28 \pm 0.5^{\circ} \mathrm{C}$ in a 14:10 h light:dark cycle. Feeding was performed twice a day with a commercial diet (Sera, Heinsberg, Germany) supplemented with Artemia sp. nauplii to promote the spawning activity. The spawning of adult zebrafish grouped in breeding tanks, containing a ratio of 2 males:1 female, was induced by the onset of lights in the morning. Embryos were rinsed in embryo water, bleached according to established protocols (Westerfield, 2007; Varga, 2011) and rinsed again to remove debris. Fertilized embryos with normal morphology were staged under a SMZ 445 stereomicroscope (Nikon, Japan) according to standard methods (Kimmel et al., 1995) and early blastula embryos ( 2.o hours post-fertilization - hpf) were statically exposed in $50 \mathrm{~mL}$ beakers, for $24 \mathrm{~h}$, to selected ketamine concentrations as well as to water system (control group). Figure 1 shows a schematic diagram of the experimental design used for embryo testing. Throughout all procedures, temperature was kept at $28 \pm 0.5^{\circ} \mathrm{C}$. 


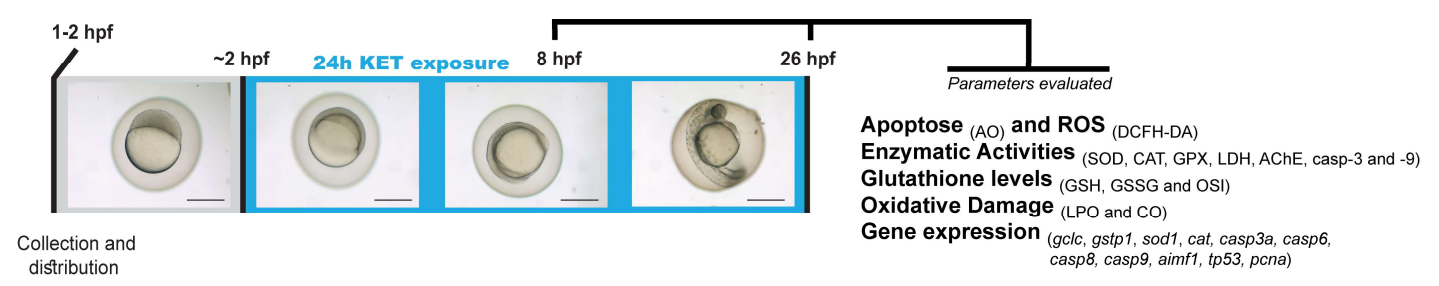

Figure 1: Schematic diagram showing the timing of ketamine exposure in zebrafish early development. Independent exposures to ketamine concentrations $(0,50,70$ or $90 \mathrm{mg} \mathrm{L}-1)$ were performed in embryo water for a period of 24 hours starting from 2 hours post-fertilization (hpf). At 8 or 26 hpf, embryos were collected, homogenised and stored at $-80^{\circ} \mathrm{C}$ until further experimentation or evaluated for distribution patterns of apoptotic cells and reactive oxygen species (acridine orange and 2,7-Dichlorodihydrofluorescein diacetate, respectively). The expression profile of oxidative stress-, apoptosis- and proliferation-related genes were examined by quantitative real-time PCR (qRT-PCR). Colorimetric detection of antioxidant enzyme activities and oxidative stress related parameters and activities of caspase- 3 and -9 were also assessed. Scale bar represents $500 \mu \mathrm{m}$.

\section{In vivo intracellular ROS and apoptosis}

Generation of reactive oxygen species (ROS) and cell death were analyzed at $26 \mathrm{hpf}$ in dechorionated zebrafish embryos (2 mg mL-1 pronase (Roche Diagnostics, Mannheim, Germany) (Westerfield, 2007) using the oxidation-sensitive fluorescent probe dye, $2^{\prime}, 7$ '-dichlorofluorescein diacetate (DCFHDA $20 \mu \mathrm{g} \mathrm{mL}-1)$ and the acridine orange ( $5 \mu \mathrm{g} \mathrm{mL}-1)$ staining, respectively for ROS and apoptosis evaluation, for 30 minutes at room temperature, according to methodologies previously described (Felix et al., 2014; Felix et al., 2016b; Felix et al., 2017c). Fluorescent images were obtained from twelve animals of each of the five replicates under an inverted microscope (IX 51 , Olympus, Antwerp, Belgium) equipped with an Olympus U-RFL-T fluorescent light source (Olympus, Antwerp, Belgium) and FITC filter, using a 4 X Olympus UIS-2 objective lens (Olympus Co., Ltd., Tokyo, Japan) and data acquired using Cell R software (Olympus, Antwerp, Belgium). Fluorescent images were processed with Adobe Photoshop CS6 (Adobe Systems, San Jose, USA). Whole-embryo fluorescence of individual embryos was quantified using the ImageJ2 program (version 2.0.0, U.S. National Institutes of Health, Bethesda, USA) (Schneider et al., 2012) after correcting for the yolk auto fluorescence.

\section{Biochemical determinations}

For biochemical determinations, at least four replicates of 100 embryos per concentration were collected at 8 and $26 \mathrm{hpf}$ as previously reported (Felix et al., 2016b). Zebrafish embryos were homogenized in cold buffer ( $0.32 \mathrm{mM}$ of sucrose, $20 \mathrm{mM}$ of HEPES, $1 \mathrm{mM}$ of $\mathrm{MgCl}_{2}$, and $0.5 \mathrm{mM}$ of phenylmethyl sulfonylfluoride (PMSF, prepared in ethanol to prevent protein degradation, $\mathrm{pH}$ 7.4) (Deng et al., 2009), using a pellet mixer and a cordless motor (VWR International, Carnaxide, Portugal). Homogenates were centrifuged at $15000 \times \mathrm{g}$ at $4^{\circ} \mathrm{C}$ for $20 \mathrm{~min}$ (Sigma model ${ }_{3} \mathrm{~K} 30$, Osterode, Germany) and supernatants (post-mitochondrial supernatant (PMS)) collected for biochemical analysis and stored at $-80^{\circ} \mathrm{C}$ for no more than 2 months until analysis. The activity of superoxide dismutase (Cu/Zn$\mathrm{SOD}$ ) was determined by the nitroblue tetrazolium (NBT) reduction generated by the 
xanthine/xanthine oxidase system at $560 \mathrm{~nm}$ (Durak et al., 1993). SOD from bovine erythrocytes was used for the construction of a standard curve (0-3.75 $\mathrm{U} \mathrm{mL-1)}$. The activity of catalase (CAT) was determined at $240 \mathrm{~nm}$ in accordance to the method previously described (Aebi, 1984) and was calculated using bovine catalase as a standard (0-5 U mL-1). Glutathione peroxidase (GPX) activity was determined at $340 \mathrm{~nm}$ (Paglia and Valentine, 1967) using the extinction coefficient of $6.22 \mathrm{mM}-1 \mathrm{~cm}-1$. For acetylcholinesterase (AChE) activity, a method described for microplates (Rodriguez-Fuentes et al., 2015) and based on Ellman's method ( $405 \mathrm{~nm}$ ) (Ellman et al., 1961) was applied using the 5-thio-2nitrobenzoic acid (TNB) extinction coefficient of $13.6 \mathrm{mM}-1 \mathrm{~cm}-1$. For lactate dehydrogenase (LDH) activity, the method described by Domingues (Domingues et al., 2010) at $340 \mathrm{~nm}$ was used using the extinction coefficient of $6.22 \mathrm{mM}-1 \mathrm{~cm}-1$. The glutathione levels were determined by measuring both the reduced (GSH) and the oxidized states (GSSG) using the fluorochrome ortho-phthalaldehyde (OPA) at $320 \mathrm{~nm}$ and $420 \mathrm{~nm}$ for excitation and emission wavelengths, respectively (Gartaganis et al., 2007). Concentrations were estimated based on GSH and GSSG standard curves (o-10 $\mu \mathrm{M}$ ). The ratio between GSH and GSSG was calculated as the oxidative-stress index (OSI). Malondealdehyde (MDA) content, an indicator of lipid peroxidation (LPO), was measured at $535 \mathrm{~nm}$ (excitation) and $550 \mathrm{~nm}$ (emission) wavelengths, by chromogenic assay by a thiobarbituric (TBA) acid-based method described elsewhere (Gartaganis et al., 2007). MDA was estimated based on a standard curve (0-4 nM) of malonaldehyde bis(dimethyl acetal). The carbonylated proteins (CO) were measured as dinitrophenylhydrazine (DNPH) derivatized protein at $370 \mathrm{~nm}$ as described by Reznick and Packer (1994) (Reznick and Packer, 1994). Determination of total ROS was performed at $485 \mathrm{~nm}$ and $530 \mathrm{~nm}$ for excitation and emission wavelengths, respectively, using the fluorescent probe DCFH-DA, as previously described (Deng et al., 2009) and ROS accumulation was estimated based on a DCF standard curve (o-6.25 nM). Caspase-3 (Ac-DEVD-pNA) and caspase-9 (Ac-LEHD-pNA) activities were measured at $405 \mathrm{~nm}$ through release of the chromophore p-nitroaniline (pNA) (Deng et al., 2009). Activities were calculated from a pNA calibration curve $(0-100 \mu \mathrm{M})$. Data were normalized by the protein content of each sample and the results expressed as fold change over control. Protein quantification in samples was performed at $595 \mathrm{~nm}$ according to the Bradford method (Bradford, 1976) with bovine serum albumin as a standard (0-1.4 mg mL-1). All samples were performed in duplicate and measured against a reagent blank in the corresponding microplate. All enzymatic assays were carried out with $20 \mu \mathrm{L}$ of sample at $30{ }^{\circ} \mathrm{C}$ using a PowerWave XS2 microplate scanning spectrophotometer (Bio-Tek Instruments, USA) or a Varian Cary Eclipse (Varian, USA) spectrofluorometer equipped with a microplate reader.

\section{Analysis of gene expression}

To determine gene expression patterns of oxidative-stress (sod1, cat, gstp1, gclc), apoptosis (casp3a, casp6, casp8, casp9, aifm1 and tp53) and cell proliferation (pcna) related genes, three independent replicates of 300 viable embryos were used and 50 animals/replica were collected at 8 and 26 hpf for qRT-PCR analysis. Total RNA was isolated from whole zebrafish embryos stored in RNAlater (Sigma, Steiheim, Germany) using the Illustra RNAspin kit (GE Healthcare, Munich, Germany) according to previously described methodologies (Luzio et al., 2013; Felix et al., 2017c). Total RNA concentration and quality (260/280 $\mathrm{nm}$ ratio $\sim 2$ ) was quantified by spectrophotometric readings at 260 and $280 \mathrm{~nm}$ in a Take3 micro-volume plate (Powerwave XS2, BioTek Instruments, Inc. USA). RNA integrity and DNA contamination were verified by gel electrophoresis, using green safe premium staining (NZYTech, Ltd., Lisbon, Portugal) and detection under UV light using BioCapt software (v99.02, Vilber Lourmat, France). The ratio between $28 \mathrm{~S} / 18 \mathrm{~S}$ bands intensity was quantified using the ImageJ2 program (version 2.0.0, U.S. National Institutes of Health, Bethesda, 
USA) (Schneider et al., 2012) and used as a measurement of quality. Only samples presenting a ratio equal or higher than 1.0 were used for further analysis. The CDNA was synthesized from $500 \mathrm{ng}$ of total RNA using the iScript cDNA synthesis kit (Bio-Rad Laboratories, California, USA) following the manufacturer's instructions. The qRT-PCR reactions were performed in triplicate using $1 \mu \mathrm{L}$ of $\mathrm{CDNA}$ as template in a $20 \mu \mathrm{L}$ reaction mixture containing $5 \times$ HOT FIREPol EvaGreen qPCR Mix Plus (Solis Biodyne, Tartu, Estonia) and $200 \mathrm{nM}$ of each specific primer (Table 1). Gene-specific primers for proliferating cell nuclear antigen (pcna) were designed using the online Primer3 primer design tool (http://primerz.ut.ee/) and analyzed by Primer-BLAST to ensure specificity for the intended target gene within the zebrafish genome. The following thermal cycling conditions were used: initial denaturation at $95^{\circ} \mathrm{C}$ for $10 \mathrm{~min}$ followed by 40 cycles of denaturation at $95^{\circ} \mathrm{C}$ for $20 \mathrm{~s}$, primer annealing for $40 \mathrm{~s}$ (annealing temperatures in Table 1 ) and extension at 72 ${ }^{\circ} \mathrm{C}$ for $20 \mathrm{~s}$ followed by a final extension at $72{ }^{\circ} \mathrm{C}$ for $5 \mathrm{~min}$. Melt curve analysis was carried out to confirm the specificity of the amplification reaction. Analysis of the results were carried out in duplicated reads using the software supplied with the Stratagene M×3005P Real-Time PCR system (Agilent Technologies, Santa Clara, USA) and the expression was calculated by normalization to the $\beta$-actin gene, used as housekeeping. Values were then normalized to the control average value calculated using the $\Delta \Delta C$ t method with efficiency correction (Pfaffl, 2001) based on standard curves of a 5 -fold dilution series prepared from a mix of the used samples. 


\section{5}

Table 1 Information of specific primers used for amplification in real-time PCR with GenBank accession numbers shown in parentheses.

\begin{tabular}{|c|c|c|c|c|c|c|c|}
\hline Function & Gene & $\begin{array}{l}\text { Forward primer } \\
\left(5^{\prime}-3^{\prime}\right)\end{array}$ & $\begin{array}{l}\text { Reverse primer } \\
\left(5^{\prime}-3^{\prime}\right)\end{array}$ & $\begin{array}{l}\text { Fragment } \\
\text { size (bp) }\end{array}$ & $\begin{array}{l}\text { Annealing } \\
\text { Temp. }\left({ }^{\circ} \mathrm{C}\right)\end{array}$ & $\mathbf{R}^{2}$ & Efficiency (\%) \\
\hline Housekeeping & B-actin (NM_181601.4) [92] & ACT GTA TTG TCT GGT GGT AC & TAC TCC TGC TTG CTA ATC C & 197 & 60 & 0.993 & 94.0 \\
\hline \multirow{4}{*}{$\begin{array}{l}\text { Oxidative } \\
\text { stress }\end{array}$} & gclc(NM_199277.2) [93] & CTA TCT GGA GAA CAT GGA GG & CAT TTT CCT CTG TTG ACC GG & 264 & 60 & 0.992 & 104.6 \\
\hline & gstp1 (NM_131734.3) [93] & TTC AGT CCA ACG CCA TGC & ATG AGA TCT GAT CAC CAA CC & 255 & 60 & 0.992 & 102.0 \\
\hline & $\begin{array}{l}\operatorname{sod} 1\left(Y_{12236.1)}\right. \\
{[94]}\end{array}$ & AAG AAG CCA GTG AAG GTG ACT & ACA TTA CCC AGG TCT CCG AC & 165 & 60 & 0.989 & 113.5 \\
\hline & $\begin{array}{l}\text { cat }\left(\mathrm{AF}_{170069.1)}\right. \\
{[94]}\end{array}$ & $\begin{array}{l}\text { AGA TGA AAC TGT GGA AGG AGG } \\
\text { GTC }\end{array}$ & AAA CAC TTT GGC TTT GGA GTA GCG & 269 & 60 & 0.990 & 110.2 \\
\hline \multirow{6}{*}{ Apoptosis } & саsp3a (NM_131877.3) [38] & CCG CTG CCC ATC ACT A & ATC CTT TCA CGA CCA TCT & 129 & 60 & 0.987 & 102.5 \\
\hline & casp6 (NM_001020497.1) [95] & AGG ACA GCG CTT CAG CAG GAC A & TGA GAG CCA TTC CCC GTC TCT TGT & 132 & 60 & 0.982 & 99.8 \\
\hline & casp8 (NM_131510.2) [96] & GGG CAA AGC TGG GAA GAT C & CTT CTT CTA GAG GAA GTC TGC & 200 & 58 & 0.995 & 106.7 \\
\hline & caspg (NM_001007404.2) [97] & CTG AGG CAA GCC ATA ATC G & AGA GGA CAT GGG AAT AGC GT & 248 & 62 & 0.987 & 102.6 \\
\hline & $\begin{array}{l}\text { aifm1 }\left(\mathrm{AY}_{422007.1)}\right. \\
{[98]}\end{array}$ & AAA GTC CGG AAA GAG GGT GT & GCC TGG AGC TCA GCA TTA AC & 224 & 60 & 0.998 & 106.8 \\
\hline & tp53 (NM_131327.2) [99] & ACC ACT GGG ACC AAA CGT AG & CAG AGT CGC TTC TTC CTT CG & 310 & 60 & 0.983 & 105.2 \\
\hline $\begin{array}{l}\text { Cell } \\
\text { Proliferation. }\end{array}$ & pcna (NM_131404.2) & GCT CGT CGG GCA TTT CT & CAG AGG AGT GGC TTT GG & 572 & 58 & 0.996 & 109.1 \\
\hline
\end{tabular}


For this study, a sample size calculation was performed with the G*Power 3 (University of Düsseldorf, Germany) based on the standard deviations from previous studies from our group (Oliveira et al., 2013; Felix et al., 2014; Santos et al., 2014). In order to detect significant changes, assuming an $\alpha$ error probability of 0.05 and a power of $90 \%$, it was determined that at least three replicates per group for gene expression and four replicates for biochemical analysis and in vivo staining procedures would be necessary. The normal distribution and the homogeneity of variances of the data were tested by Kolmogorov-Smirnov and Levene's tests, respectively. When data did not accomplish the previous assumptions, groups were compared by a non-parametric independent samples test, Kruskal-Wallis, followed by Dunn's pairwise comparison tests and data expressed as median and interquartile range (25th; 75th percentiles). Data normally distributed was analysed by a one-way analysis of variance (ANOVA) followed by Tukey's pairwise comparison tests and data expressed as mean \pm standard deviation. In the representation of data following normal and non-normal distributions, both are expressed as median and interquartile range as it is a more conservative approach. All tests performed were two-tailed and statistical analyses were carried out using SPSS for Windows (Version 22.0; Chicago, IL, USA) and differences were considered significant at $\mathrm{p}<0.05$.

\section{RESULTS}

\section{In vivo embryonic apoptosis and ROS}

In vivo assays for apoptosis and ROS patterns were performed at $26 \mathrm{hpf}$. Acridine orange staining photographs of the zebrafish embryos (Figure $2 \mathrm{~A}$ ) showed that embryos exposed to ketamine exhibited a dose-dependent delay in development as well as a dose-dependent increase $\left(X_{2}(3)=13.15\right.$, $\mathrm{p}=0.004)$ in overall apoptosis patterns. In this regard, a higher fluorescence intensity was observed in the embryos exposed to $70(p=0.028)$ and $90 \mathrm{mg} \mathrm{L}-1(p=0.001)$ ketamine comparatively to the control group. Differences in fluorescence intensity were also observed between embryos exposed to the lowest and the highest ketamine concentration $(p=0.011)$. Overall, apoptosis in ketamine exposed embryos was mainly observed in the tail, fins, pericardium zone and hindbrain and in the midbrain. The ROS distribution in control and ketamine exposed embryos showed a similar distribution $(F(3,13)=1.19, p=0.362)$, as seen in DCFH-DA stained embryos (Figure $2 B$ ). 


\section{A}
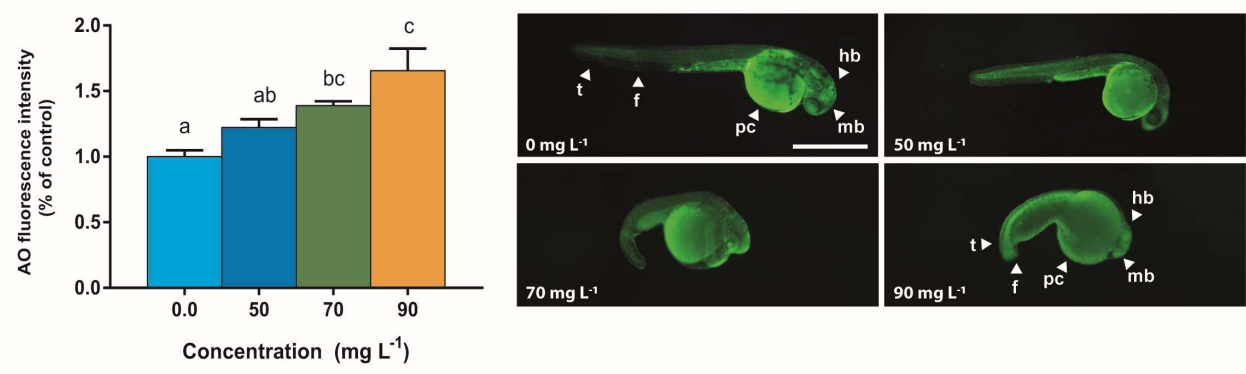

B

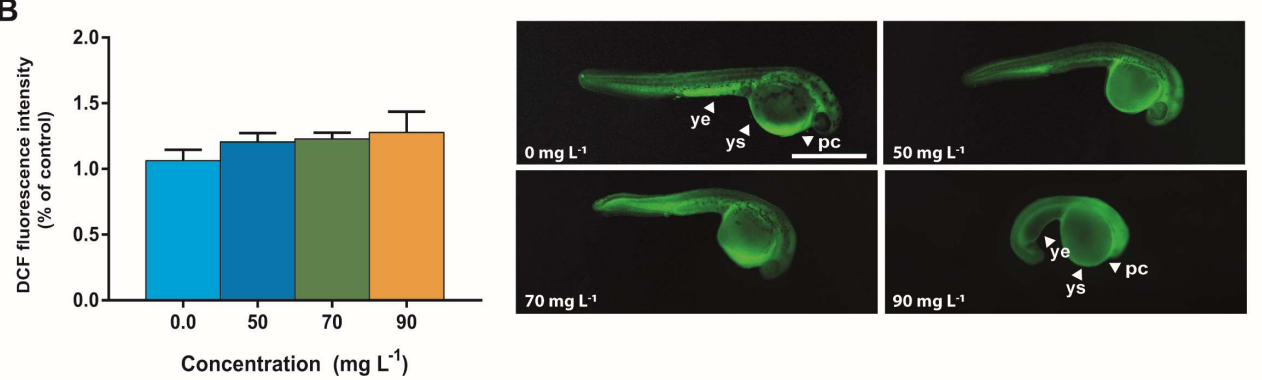

Figure 2: Quantification and distribution of apoptotic cells (A) and reactive oxygen species (B) in $26 \mathrm{hpf}$ zebrafish embryos after exposure to ketamine for $\mathbf{2 4}$ hours. Data represented as median an interquartile range from at least four independent samples ( $n=12$ embryos/each) and expressed as fold-change of control. Statistical analysis was performed using one-way ANOVA followed by Tukey's multiple-comparison test or using the Kruskal-Wallis test followed by Dunn's test. Different lowercase letters indicate significant differences between groups $(p<0.05)$. An increasing number of apoptotic cells stained with acridine orange was observed in the tail $(t)$, fins $(\mathrm{f})$, pericardial zone $(\mathrm{pc})$, hindbrain $(\mathrm{hb})$ and midbrain $(\mathrm{mb})$ with increasing ketamine concentrations. The pericardial (pc), yolk sac (ys) and yolk extension (ye) were the zones were an increase in the ROS distribution (DCFH-DA staining) was detected. Scale bar represents $500 \mu \mathrm{m}$.

\section{Oxidative stress and apoptosis related biomarkers}

The ROS production, enzymatic determinations, glutathione levels and oxidative damage biomarkers were measured in embryos at 8 and $26 \mathrm{hpf}$ and the results are presented in Figure 3 . Nonsignificant differences between groups are presented in Table $\mathrm{S}_{1}$. In comparison to the control group, the activities of SOD (26.5 $\pm 3.91 \mathrm{U}$ mg protein-1) and CAT (47.6 [46.4-60.1] U mg protein-1) at $8 \mathrm{hpf}$ were dose-dependently increased $\left(X_{2}(3)=12.16, p=0.007\right.$ and $F(3,18)=10.40, p<0.001$ for SOD and CAT, respectively) in embryos exposed to ketamine ( $p=0.011$ for $50 \mathrm{mg} L-1, p=0.017$ for $70 \mathrm{mg} L-1$ and $p=0.001$ for $90 \mathrm{mg} \mathrm{L}-1$ for $S O D ; p=0.032$ for $70 \mathrm{mg} \mathrm{L}-1$ and $p=0.001$ for $90 \mathrm{mg} \mathrm{mL}-1$ for $(A T)$ ). Likewise, GSSG levels were increased $\left(X_{2}(3)=9.30, p=0.026\right)$ at the same time-point relatively to the control group ( 94.5 [77.0-124] nmol mg protein-1) $(p=0.018$ and $p=0.004$ for $70 \mathrm{mg} \mathrm{L-1}$ and $90 \mathrm{mg} \mathrm{L-1}$, respectively). The levels of protein carbonyls were found to be significantly decreased $(F(3,18)=5.18$, $\mathrm{p}=0.009)$ in 50 and $70 \mathrm{mg} \mathrm{L}-1$ compared with levels observed in the control group $(64.0 \pm 12.5 \mathrm{nmol} \mathrm{mg}$ protein -1$)(p=0.007$ and $p=0.037$, respectively). Also at $8 \mathrm{hpf}$, the activity of caspase- 9 was reduced $(F(3,18)=6.72, p=0.004)$ in the groups 50 and $90 \mathrm{mg} \mathrm{L}-1 \quad(p=0.005$ and $p=0.014$, respectively) comparatively to the control group (41.1 [27.6-52.2] nmol pNA mg protein-1). At $26 \mathrm{hpf}$, all these differences disappeared. Notwithstanding, a dose-dependent increase in ROS production $(F(3,21)=6.29, p=0.003)$ was observed at 26 hpf with 70 and $90 \mathrm{mg} \mathrm{L-1}$ groups showing significantly 
differences from the control group (310 [265-415] nmol DCF mg protein- 1 ) $(p=0.008$ and $p=0.004$, respectively). An increase of caspase-3 activity $(F(3,18)=8.16, p=0.002)$ for the lowest concentration group was also observed at $26 \mathrm{hpf}(\mathrm{p}=0.009)$ comparatively to the control group $(18.6 \pm 2.08 \mathrm{nmol} \mathrm{mg}$ protein-1). Although slightly variations in the remaining parameters were observed, no statistically significant differences were observed.
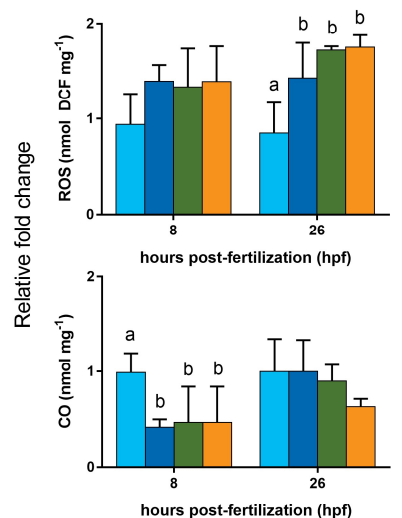

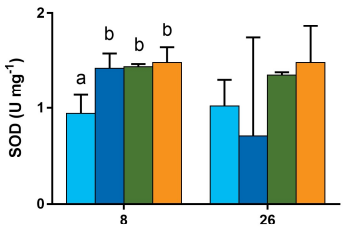

hours post-fertilization (hpf)

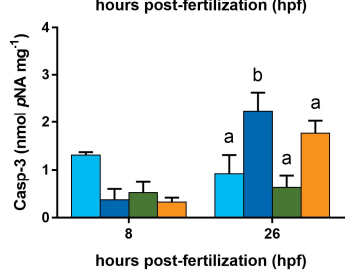

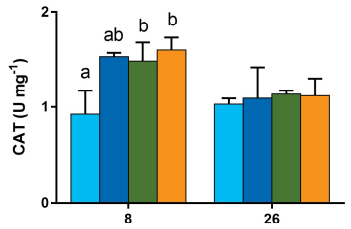

hours post-fertilization (hpf)

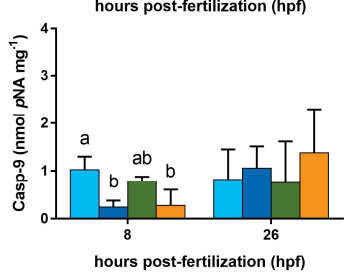

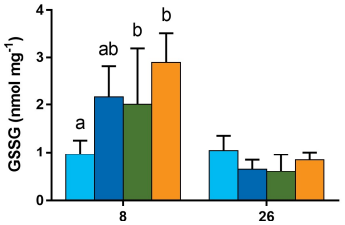

hours post-fertilization (hpf)

๘ $0 \mathrm{mg} \mathrm{L}^{-1}$

$50 \mathrm{mg} \mathrm{L}^{-1}$

ए $70 \mathrm{mg} \mathrm{L}^{-1}$

ש $90 \mathrm{mg} \mathrm{L}^{-1}$

Figure 3: Reactive oxygen species (ROS) and specific activities of superoxide dismutase (SOD), catalase (CAT), oxidized glutathione (GSSG), casp-3and -9, and levels of protein carbonyl (CO) at 8 and $26 \mathrm{hpf}$. Data represented as median an interquartile range from at least four independent samples (100 embryos/each) and expressed as fold-change of control. Statistical analysis was performed using one-way ANOVA followed by Tukey's multiple-comparison test or using the Kruskal-Wallis test followed by Dunn's test. Different lowercase letters indicate significant differences between groups $(p<0.05)$.

\section{Gene expression profile}

The statistically significant differences in expression levels of the studied genes are summarized in Figure 4 while remaining results are presented in Table $\mathrm{S}_{2}$. Changes in the expression patterns of sod 1 at $8(F(3,10)=4.81, p=0.025)$ and $26 \mathrm{hpf}(F(3,10)=7.82, p=0.003)$ as well as in the cat levels at 8 $(F(3,10)=7.36, p=0.007)$ and 26 hpf $(F(3,10)=8.73, p=0.002)$ were observed. The highest dose of ketamine induced an increase of sod 1 gene expression at $8 \mathrm{hpf}(\mathrm{p}=0.030)$ and an inhibition at $26 \mathrm{hpf}$ $(p=0.013)$ comparatively to the control group (relative expression of $1.35 \pm 0.02$ and $1.38 \pm 0.05$ at 8 and $26 \mathrm{hpf}$, respectively). A significant increase in cat mRNA levels was observed at $8 \mathrm{hpf}$ in the groups exposed to $50 \mathrm{mg} \mathrm{mL-1}(p=0.027)$ compared to the control group (relative expression of $1.35 \pm 0.02$ ). At $26 \mathrm{hpf}$, a significant down-regulation of cat gene was observed for the 50 and $90 \mathrm{mg} \mathrm{mL}-1$ groups $(p=0.004$ and $p=0.008$, respectively) compared to the control group (relative expression of $1.38 \pm 0.05$ ). The expression of apoptosis-related genes was also affected by ketamine exposure. Almost a 2-fold increase regarding control group (relative expression of 1.31 \pm 0.03 ) was observed in the levels of casp6 mRNA at $8 \mathrm{hpf}(\mathrm{F}(3,8)=5.65, \mathrm{p}=0.022)$ in the highest ketamine group $(\mathrm{p}=0.029)$. Changes in the levels of caspg gene were also affected by ketamine exposure at $8(F(3,8)=11.54, p=0.003)$ and $26 \mathrm{hpf}$ $(F(3,8)=8.24, p=0.008)$. In this regard, the expression of caspg gene was increased at $8 \mathrm{hpf}(\mathrm{p}=0.003)$ and at $26 \mathrm{hpf}(\mathrm{p}=0.009)$ by the highest ketamine dose compared to the control group (relative expression of $1.52 \pm 0.02$ and $1.58 \pm 0.03$, respectively). At $8 \mathrm{hpf}$, the levels of tp53 mRNA were increased $(F(3,8)=12.77, p=0.002)$ after exposure to $70(p=0.024)$ and $90 \mathrm{mg} \mathrm{mL}-1 \quad(p=0.005)$ of 
ketamine compared to the control group (relative expression of 1.21 \pm 0.02 ). No other statistically significant differences were observed for the remaining genes.
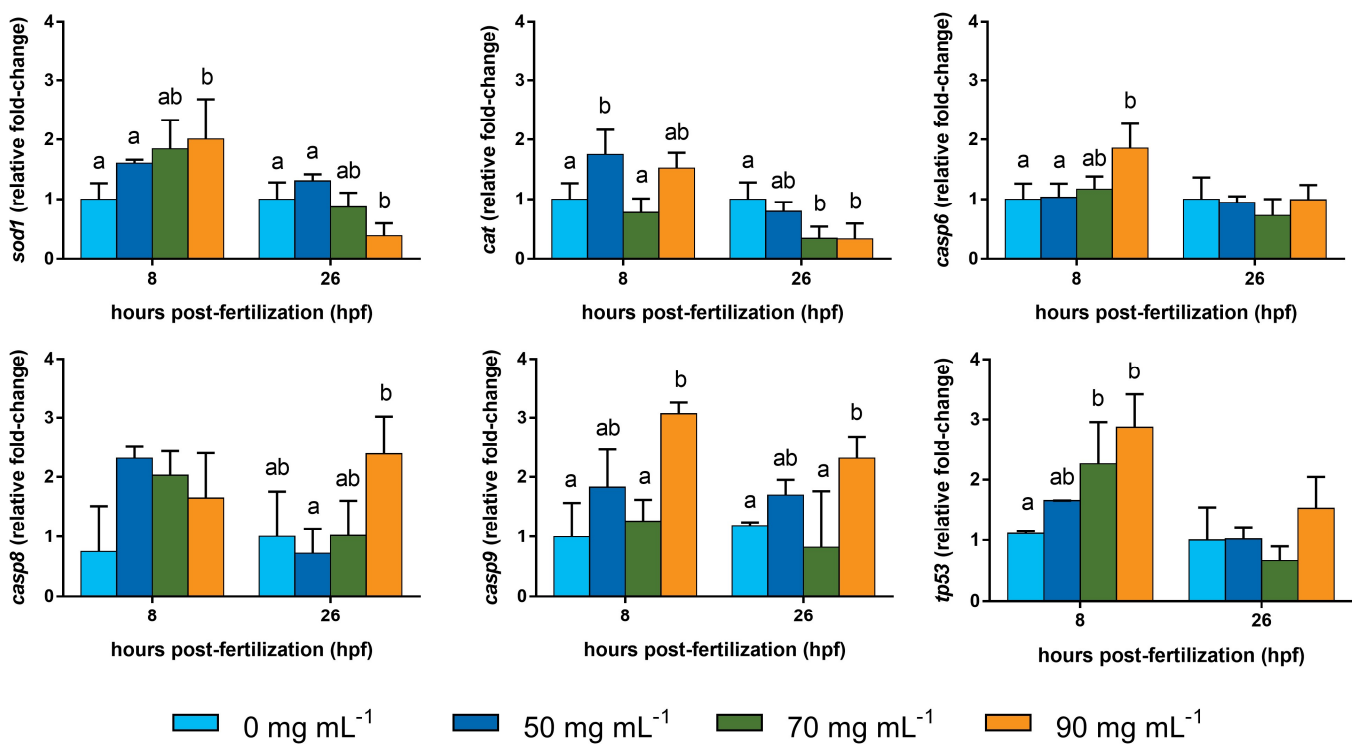

Figure 4: RNA transcript levels of genes related to oxidative stress (sod1 and cat) and apoptosis (casp6, casp8, caspg and tp53) following exposure to ketamine. Gene expression changes were analysed at 8 and $26 \mathrm{hpf}$ and normalized to $\beta$-actin levels. Data represented as median an interquartile range resultant of three independent samples ( 50 embryos/each). Statistical analysis was performed using one-way ANOVA followed by Tukey's multiple-comparison test or using the Kruskal-Wallis test followed by Dunn's test. Different lowercase letters indicate significant differences between groups $(p<0.05)$. 


\section{DISCUSSION}

In the present study, the mechanisms of ketamine-induced oxidative stress and apoptosis were examined following a 24 -hour exposure. To our knowledge, this is the first study to examine the effects of a long ketamine exposure in such early development stages of this aquatic model regarding oxidative stress and cellular death. The results of this work show that ketamine exposure during a 24 hours' period during early organogenesis of zebrafish induced, besides abnormal development (Felix et al., 2017b), changes in enzymatic biomarkers in addition to a substantial impact on the expression of oxidative stress- and apoptotic-related genes. The concentrations of ketamine used in this study are not routinely detected in aquatic systems (peak concentrations of ketamine have been reported up to about $140 \mu \mathrm{g} \mathrm{L-1} \mathrm{(Jiang} \mathrm{et} \mathrm{al.,} \mathrm{2015).} \mathrm{Nevertheless,} \mathrm{a} \mathrm{deterministic} \mathrm{approach} \mathrm{(risk} \mathrm{quotient-RQ)}$ to compare the estimated environmental exposure to a toxicity end-point value, such as the LC50 (Peterson, 2006) suggest that there is no ecotoxicological risk for the aquatic environment $(R Q<1)$ (Escher et al., 2011). However, the exposure of animals to effective concentrations such as LC 50 is a critical step in the identification and prediction of the impacts of chemicals showing cumulative timedependent toxicological risk and potential (Tennekes, 2017). In fact, ketamine is likely to accumulate in the environment due to its half-life higher that could be more than $10 \mathrm{~h}$ (Wang and Lin, 2014) and to its resistance to degradation (Liao et al., 2017) thereby increasing the risk of environmental impact. Although this approach to toxicity testing is based on a concentration-effect relationship which may overestimate the toxicological impact of low exposure concentrations (Zurlo, 2012), it allows further understanding of the underlying mechanisms. Additionally, the approach used in this study can be particularly useful for identifying the doses of toxicological concern of emerging environmental contaminants (Richardson and Ternes, 2014; de Jesus Gaffney et al., 2015; Gavrilescu et al., 2015).

The early zebrafish development is a complex process driven by a highly coordinated cascade of events (Bonneau et al., 2011). The redox balance is essential to the embryonic development by playing defined functions in signaling pathways such as proliferation, differentiation, cell death, and migration (Dennery, 2007; Covarrubias et al., 2008; Dennery, 2010). It is well established that SOD and CAT are important enzymes acting together to reduce ROS (Slaninova et al., 2009). In accordance with this principle, the dose-dependent increase in SOD and CAT activity, observed after $6 \mathrm{~h}$ of ketamine exposure, caused a delayed in ROS accumulation. Even though no differences in spatial distribution of ROS were observed in vivo by DCFH-DA staining, the results suggest an adaptive response to ketamine, promoted through the antioxidant enzymes activity increase as an attempt to eliminate surplus reactive radicals. Previous data has also shown that ketamine induces oxidative stress responses in medaka (Oryzias latipes) embryos following 7 days of exposure to environmentally relevant concentrations (Liao et al., 2015). Furthermore, an up-regulation of sod1 and cat genes was observed at $8 \mathrm{hpf}$ whereas a downregulation of mRNA levels of both genes was observed at $26 \mathrm{hpf}$. This may represent a dual response of the embryo to ketamine exposure by augmenting transcript levels until a threshold value above which the transcript levels underlie the augmented levels of ROS. 
Notwithstanding, a decrease in protein carbonyls was observed for the lowest doses suggesting a protective mechanism to lower the negative effects of ROS induced by ketamine. Additionally, changes in glutathione homeostasis were observed during ketamine exposure but alterations in the oxidative stress ratio (GSH/GSSG ratio) and in the expression of the glutathione biosynthetic gene (gclc) were not perceived. The glutathione redox system is tightly regulated during embryonic development (Hansen and Harris, 2015) and it is important for maintaining the biological state of a cell. The balance between GSH and GSSG is maintained intracellularly through the action of several additional enzymes and compounds that, when disrupted, affect several redox-signaling mechanisms (Schafer and Buettner, 2001; Jones, 2002). Despite the relation between the cellular redox state and an abnormal embryo development, the underlying mechanism is not entirely understood (Hansen and Harris, 2015). Based on the results of the present work, a mechanism is proposed in which ketamine stimulate hydrogen peroxide production. Then the levels of GSSG increase, as observed, as an attempt to maintain the glutathione cycle balance. Supporting this hypothesis, previous studies have also reported ketamine to induce hydrogen peroxide generation in other organisms (Venancio et al., 2015), but more extensive examination is needed to further establish this association.

According to the literature (Schafer and Buettner, 2001; Dennery, 2007, 2010), changes in the cellular redox environment can impact embryonic development by shifting the fate of cells in the embryo toward proliferation, differentiation or cellular death. Therefore, proliferation is favored by a reduced oxidative state whereas differentiation and cell death are favored by mild and high oxidative settings, respectively. The results of the present study suggest a general change to a more oxidized environment induced by ketamine exposure. Thus, in agreement, it was expected to observe an increase in apoptosis rather than proliferation and differentiation. Indeed, no changes in proliferation were observed as confirmed by the outcome of pcna gene expression while changes in apoptosisrelated genes were detected. Accordingly, the gene expression of casp6, caspg and tp53 were significantly increased and a trend to increase casp8 transcript levels was observed during ketamine exposure.

Typically, p53 integrates a variety of signals that control lethality and teratology (Choi and Donehower, 1999). Furthermore, P53 activates the apoptotic machinery through stimulation of cytochrome c release from mitochondria (Schuler et al., 2000; Mihara et al., 2003) which promotes the activation of caspase-9 (Jiang and Wang, 2000). Active caspase- 9 then prompts an executioner caspase activation cascade (caspase-3, -6 and -7) (Cullen and Martin, 2009; Mcllwain et al., 2013). Caspase- 6 has been established as a major activator of caspase- 8 in vivo which in turn has an important role in the positive feedback loop linking caspase activation to mitochondrial dysfunction (Cowling and Downward, 2002). Yet, caspase-6 can regulate its own activity through unique intramolecular mechanism of self-activation (Klaiman et al., 2009; Edgington et al., 2012). Taking in regard the above, and the outcomes of this study concerning alterations in the caspases activity and expression, it is hypothesized that ketamine-induced apoptosis not only involves the mitochondrial pathway, as described in vitro (Braun et al., 2010), but it also occurs via p53-dependent pathway, as previously reported in developing rats (Yan et al., 2014). This is also supported by the observed transient increase in GSSG levels which precede cytochrome $\mathrm{c}$ release and apoptosis activation (Pias and $A w, 2002)$.

(1) 
Moreover, the AO staining assay was consistent with gene expression patterns observed thus confirming ketamine-induced apoptosis. Still, variations in caspase- 9 catalytic activity were observed and further investigation is needed as it is known that caspase catalytic activity is regulated by many cellular processes (Shi, 2002, 2004). Notwithstanding, the increase of caspase- 9 activity could be a self-protective mechanism by which caspase- 9 catalytic activity attempts to avoid caspase- 9 release from the apoptosome. Moreover, severe developmental defects, similar to the ones observed when zebrafish embryos were exposed to ketamine (Felix et al., 2014), have been associated to abnormal glycolysis (Xu et al., 2014; Xu et al., 2016), the predominant source of energy during these early stages of zebrafish (Stackley et al., 2011). As such, prior to the MBT, there is a potential for oxidative damage to occur as embryos switch from anaerobic to aerobic metabolism (Stackley et al., 2011). Still, little is known about the interaction between toxic compounds and this pathway in zebrafish development. Notwithstanding, evidence in the literature supports a critical function of p53 in the development of the nervous system at later matured stages by regulating the proliferation and differentiation of neural progenitor cells (Jacobs et al., 2006; Tedeschi and Di Giovanni, 2009). Indeed, an up-regulation of p53-related apoptotic genes in neural crest progenitors has been associated with abnormal zebrafish development (Rinon et al., 2011). Furthermore, ketamine has been shown to alter the neurogenesis in zebrafish through possible interactions with notch1a or gli2b (Cuevas et al., 2013; Kanungo et al., 2013). Notch signaling is involved in a variety of cell-fate decisions for nervous system development through a p53-dependent mechanism (Yang et al., 2004). Again, this apparent interconnection seems to corroborate a model in which p53 signaling plays an important role in ketamine toxicity. In accordance, a recent study has shown that ketamine induces the disruption of p53-regulated apoptosis pathways in medaka larvae (Liao et al., 2017). Nevertheless, interactions with other signaling pathways could not be excluded. For instance, calcium signaling plays an essential role in the development of the nervous system (West et al., 2001; Toth et al., 2016) and it also mediates the activation of p53 (Liu et al., 2007). Also, previous published data highlighted the teratogenic potential of ketamine by showing dose-dependent and stage-specific malformed phenotypes accompanied by changes in molecular markers associated with distinct signals related to oxidative stress, osmoregulation and apoptosis processes (Felix et al., 2014; Felix et al., 2016a; Felix et al., 2016b; Felix et al., 2017a; Felix et al., 2017b; Felix et al., 2017c). Although further research using different technical approaches is needed to clarify the pathways and molecular mechanisms of p53 signals involved, it could be hypothesized a dual mechanism for the teratogenic effects of ketamine (Fig. 5) derived from abnormal energy metabolism during these early stages of development.

In summary, a stage-dependent mechanism by which ketamine triggers the transcriptional activation of $\mathrm{p}_{53}$ in response to ketamine-induced oxidative stress is proposed. It is suggested that ketamine induces a threshold of oxygen-free radicals above endurable one, leading to massive cell death. The results of this study extend the current knowledge on ketamine toxicological effects that may be useful in risk assessment procedures. Further investigation on the toxic effects to aquatic species and human health should be undertaken, due to the complex interactions of combined illicit drugs in aquatic ecosystems and unexpected pharmacological interactions. 


\section{5}

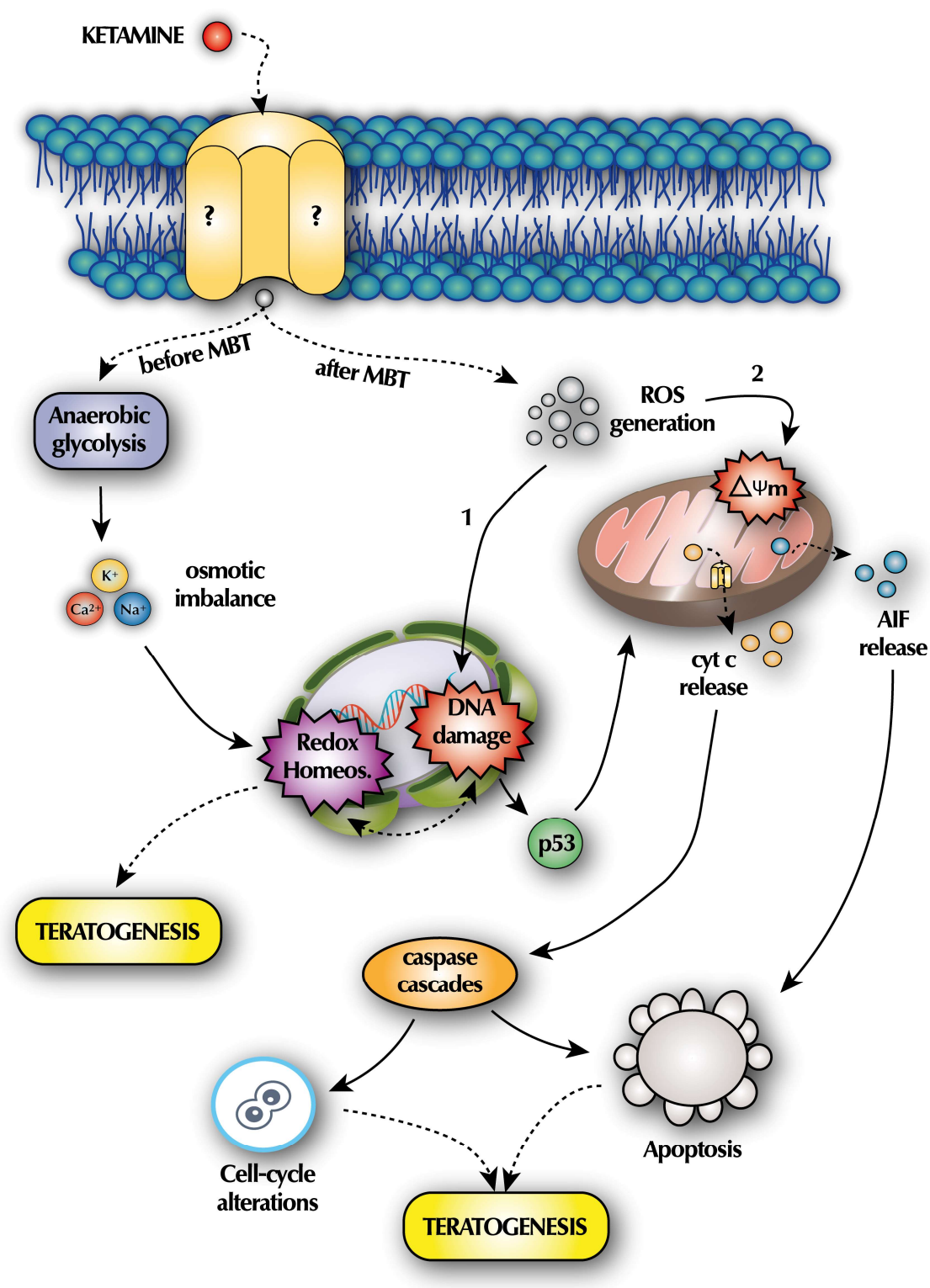

Figure 5: The possible mechanism for ketamine teratogenicity during early developmental phases based on the results from this and other studies presented in the discussion. Although ketamine membrane functional specificity remains elusive, it is proposed a mechanism in which ketamine affects energy metabolism during development. An interruption of the glycolytic pathway may affect the metabolic networks of the cell affecting redox homeostasis and/or causing DNA damage with consequent teratogenic effects. On the other hand, an increase in reactive oxygen species (ROS) may induce two different molecular mechanisms. One, in which DNA damage is involved in $\mathrm{p} 53$ activation and the consequent initiation of the extrinsic apoptotic signalling (1), and another, in which ROS-induced mitochondrial depolarization triggers the same death signals (2). Both ultimately result in teratogenesis by cell-cycle alterations or cellular death 


\section{Acknowledgements}

This work was supported by European Investment Funds by FEDER/COMPETE/POCl- Operational Competitiveness and Internationalization Programme, under Project POCl-01-0145-FEDER-006958 and FCOMP-01-0124-FEDER-028683 and National Funds by FCT - Portuguese Foundation for Science and Technology, under the projects PTDC/CVT-WEL/4672/2012 and UID/AGR/04033/2013 and by individual funding provided by postdoctoral fellowship SFRH/BPD/103006/2014 issued by FCT.

\section{REFERENCES}

Aebi, H., 1984. Catalase in vitro. Methods Enzymol. 105, 121-126.

Arnold, S.M., Greggs, B., Goyak, K.O., Landenberger, B.D., Mason, A.M., Howard, B., Zaleski, R.T., 2017. A quantitative screening-level approach to incorporate chemical exposure and risk into alternative assessment evaluations. Integr. Environ. Assess. Manag. 13, 1007-1022.

Bonneau, B., Popgeorgiev, N., Prudent, J., Gillet, G., 2011. Cytoskeleton dynamics in early zebrafish development: A matter of phosphorylation? Bioarchitecture 1, 216-220.

Bradford, M.M., 1976. A rapid and sensitive method for the quantitation of microgram quantities of protein utilizing the principle of protein-dye binding. Anal. Biochem. 72, 248-254.

Braun, S., Gaza, N., Werdehausen, R., Hermanns, H., Bauer, I., Durieux, M.E., Hollmann, M.W., Stevens, M.F., 2010. Ketamine induces apoptosis via the mitochondrial pathway in human lymphocytes and neuronal cells. Br. J. Anaesth. 105, 347-354.

Castiglioni, S., Borsotti, A., Senta, I., Zuccato, E., 2015. Wastewater analysis to monitor spatial and temporal patterns of use of two synthetic recreational drugs, ketamine and mephedrone, in Italy. Environ. Sci. Technol. 49, 5563-5570.

Chakraborty, C., Hsu, C.H., Wen, Z.H., Lin, C.S., Agoramoorthy, G., 2009. Zebrafish: a complete animal model for in vivo drug discovery and development. Curr. Drug Metab. 10, 116-124.

Choi, J., Donehower, L.A., 1999. p53 in embryonic development: maintaining a fine balance. Cell. Mol. Life Sci. 55, 38-47.

Covarrubias, L., Hernandez-Garcia, D., Schnabel, D., Salas-Vidal, E., Castro-Obregon, S., 2008. Function of reactive oxygen species during animal development: passive or active? Dev. Biol. 320, 1-11.

Cowling, V., Downward, J., 2002. Caspase-6 is the direct activator of caspase-8 in the cytochrome c-induced apoptosis pathway: absolute requirement for removal of caspase-6 prodomain. Cell Death Differ. 9, 10461056. 
Cuevas, E., Trickler, W.J., Guo, X., Ali, S.F., Paule, M.G., Kanungo, J., 2013. Acetyl L-carnitine protects motor neurons and Rohon-Beard sensory neurons against ketamine-induced neurotoxicity in zebrafish embryos. Neurotoxicol. Teratol. 39, 69-76.

Cullen, S.P., Martin, S.J., 2009. Caspase activation pathways: some recent progress. Cell Death Differ. 16, 935-938.

Dai, Y.J., Jia, Y.F., Chen, N., Bian, W.P., Li, Q.K., Ma, Y.B., Chen, Y.L., Pei, D.S., 2014. Zebrafish as a model system to study toxicology. Environ. Toxicol. Chem. 33, 11-17.

de Jesus Gaffney, V., Almeida, C.M., Rodrigues, A., Ferreira, E., Benoliel, M.J., Cardoso, V.V., 2015. Occurrence of pharmaceuticals in a water supply system and related human health risk assessment. Water Res. 72, 199-208.

Deng, J., Yu, L., Liu, C., Yu, K., Shi, X., Yeung, L.W., Lam, P.K., Wu, R.S., Zhou, B., 2009. Hexabromocyclododecane-induced developmental toxicity and apoptosis in zebrafish embryos. Aquat. Toxicol. 93, 29-36.

Dennery, P.A., 2007. Effects of oxidative stress on embryonic development. Birth Defects Res. C. Embryo Today $81,155-162$.

Dennery, P.A., 2010. Oxidative stress in development: nature or nurture? Free Radic. Biol. Med. 49, 11471151

Domingues, I., Oliveira, R., Lourenco, J., Grisolia, C.K., Mendo, S., Soares, A.M., 2010. Biomarkers as a tool to assess effects of chromium (VI): comparison of responses in zebrafish early life stages and adults. Comp. Biochem. Physiol. C Toxicol. Pharmacol. 152, 338-345.

Durak, I., Yurtarslanl, Z., Canbolat, O., Akyol, O., 1993. A methodological approach to superoxide dismutase (SOD) activity assay based on inhibition of nitroblue tetrazolium (NBT) reduction. Clin. Chim. Acta 214, 103104 .

Edgington, L.E., van Raam, B.J., Verdoes, M., Wierschem, C., Salvesen, G.S., Bogyo, M., 2012. An optimized activity-based probe for the study of caspase-6 activation. Chem. Biol. 19, 340-352.

Ellman, G.L., Courtney, K.D., Andres, V., Jr., Feather-Stone, R.M., 1961. A new and rapid colorimetric determination of acetylcholinesterase activity. Biochem. Pharmacol. 7, 88-95.

Escher, B.I., Baumgartner, R., Koller, M., Treyer, K., Lienert, J., McArdell, C.S., 2011. Environmental toxicology and risk assessment of pharmaceuticals from hospital wastewater. Water Res. 45, 75-92.

Felix, L.M., Antunes, L.M., Coimbra, A.M., 2014. Ketamine NMDA receptor-independent toxicity during zebrafish (Danio rerio) embryonic development. Neurotoxicol. Teratol. 41, 27-34.

Felix, L.M., Antunes, L.M., Coimbra, A.M., Valentim, A.M., 2017a. Behavioral alterations of zebrafish larvae after early embryonic exposure to ketamine. Psychopharmacology (Berl.) 234, 549-558. 
Felix, L.M., Serafim, C., Martins, M.J., Valentim, A.M., Antunes, L.M., Matos, M., Coimbra, A.M., 2017 b. Morphological and behavioral responses of zebrafish after $24 \mathrm{~h}$ of ketamine embryonic exposure. Toxicol. Appl. Pharmacol. 321, 27-36.

Felix, L.M., Serafim, C., Valentim, A.M., Antunes, L.M., Campos, S., Matos, M., Coimbra, A.M., $2016 a$. Embryonic stage-dependent teratogenicity of ketamine in zebrafish (Danio rerio). Chem. Res. Toxicol. 29, 1298-1309.

Felix, L.M., Serafim, C., Valentim, A.M., Antunes, L.M., Matos, M., Coimbra, A.M., 2017c. Apoptosis-related genes induced in response to ketamine during early life stages of zebrafish. Toxicol. Lett. 279, 1-8.

Felix, L.M., Vidal, A.M., Serafim, C., Valentim, A.M., Antunes, L.M., Campos, S., Matos, M., Monteiro, S.M., Coimbra, A.M., 2016b. Ketamine-induced oxidative stress at different developmental stages of zebrafish (Danio rerio) embryos. Rsc Advances 6, 61254-61266.

Fent, K., Weston, A.A., Caminada, D., 2006. Ecotoxicology of human pharmaceuticals. Aquat. Toxicol. 76, 122-159.

Gartaganis, S.P., Patsoukis, N.E., Nikolopoulos, D.K., Georgiou, C.D., 2007. Evidence for oxidative stress in lens epithelial cells in pseudoexfoliation syndrome. Eye 21, 1406-1411.

Gavrilescu, M., Demnerova, K., Aamand, J., Agathos, S., Fava, F., 2015. Emerging pollutants in the environment: present and future challenges in biomonitoring, ecological risks and bioremediation. $\mathrm{N}$ Biotechnol 32, 147-156.

Grandjean, P., Barouki, R., Bellinger, D.C., Casteleyn, L., Chadwick, L.H., Cordier, S., Etzel, R.A., Gray, K.A., Ha, E.H., Junien, C., Karagas, M., Kawamoto, T., Paige Lawrence, B., Perera, F.P., Prins, G.S., Puga, A., Rosenfeld, C.S., Sherr, D.H., Sly, P.D., Suk, W., Sun, Q., Toppari, J., van den Hazel, P., Walker, C.L., Heindel, J.J., 2015. Life-long implications of developmental exposure to environmental stressors: New perspectives. Endocrinology 156, 3408-3415.

Guo, R., Liu, G., Du, M., Shi, Y., Jiang, P., Liu, X., Liu, L., Liu, J., Xu, Y., 2016. Early ketamine exposure results in cardiac enlargement and heart dysfunction in Xenopus embryos. BMC Anesthesiol 16, 23.

Hansen, J.M., Harris, C., 2015. Glutathione during embryonic development. Biochim. Biophys. Acta 1850, 1527-1542.

Jacobs, W.B., Kaplan, D.R., Miller, F.D., 2006. The p53 family in nervous system development and disease. J. Neurochem. 97, 1571-1584.

Jansen, K.L., 2000. A review of the nonmedical use of ketamine: use, users and consequences. J. Psychoactive Drugs 32, 419-433.

Jiang, J.J., Lee, C.L., Fang, M.D., 2014. Emerging organic contaminants in coastal waters: anthropogenic impact, environmental release and ecological risk. Mar. Pollut. Bull. 85, 391-399. 
Jiang, J.J., Lee, C.L., Fang, M.D., Tu, B.W., Liang, Y.J., 2015. Impacts of emerging contaminants on surrounding aquatic environment from a youth festival. Environ. Sci. Technol. 49, 792-799.

Jiang, X., Wang, X., 2000. Cytochrome c promotes caspase-9 activation by inducing nucleotide binding to Apaf-1. J. Biol. Chem. 275, 31199-31203.

Jones, D.P., 2002. Redox potential of GSH/GSSG couple: assay and biological significance. Methods Enzymol. 348, 93-112.

Kanungo, J., Cuevas, E., Ali, S.F., Paule, M.G., 2013. Ketamine induces motor neuron toxicity and alters neurogenic and proneural gene expression in zebrafish. J. Appl. Toxicol. 33, 410-417.

Kimmel, C.B., Ballard, W.W., Kimmel, S.R., Ullmann, B., Schilling, T.F., 1995. Stages of embryonic development of the zebrafish. Dev. Dyn. 203, 253-310.

Klaiman, G., Champagne, N., LeBlanc, A.C., 2009. Self-activation of Caspase- 6 in vitro and in vivo: Caspase6 activation does not induce cell death in HEK293T cells. Biochim. Biophys. Acta 1793, 592-601.

Liao, P.H., Hwang, C.C., Chen, T.H., Chen, P.J., 2015. Developmental exposures to waterborne abused drugs alter physiological function and larval locomotion in early life stages of medaka fish. Aquat. Toxicol. 165, 8492.

Liao, P.H., Yang, W.K., Yang, C.H., Lin, C.H., Hwang, C.C., Chen, P.J., 2017. Illicit drug ketamine induces adverse effects from behavioral alterations and oxidative stress to p53-regulated apoptosis in medaka fish under environmentally relevant exposures. Environ. Pollut.

Lin, A.Y.-C., Lee, W.-N., Wang, X.-H., 2014a. Ketamine and the metabolite norketamine: Persistence and phototransformation toxicity in hospital wastewater and surface water. Water Res. 53, 351-360.

Lin, A.Y., Lee, W.N., Wang, X.H., 2014b. Ketamine and the metabolite norketamine: persistence and phototransformation toxicity in hospital wastewater and surface water. Water Res. 53, 351-360.

Lin, A.Y., Wang, X.H., Lin, C.F., 2010. Impact of wastewaters and hospital effluents on the occurrence of controlled substances in surface waters. Chemosphere 81, 562-570.

Liu, C., Xu, H., Lam, S.H., Gong, Z., 2013. Selection of reliable biomarkers from PCR array analyses using relative distance computational model: methodology and proof-of-concept study. PLoS ONE 8, e83954.

Liu, Z.M., Chen, G.G., Vlantis, A.C., Tse, G.M., Shum, C.K., van Hasselt, C.A., 2007. Calcium-mediated activation of $\mathrm{Pl}_{3} \mathrm{~K}$ and $\mathrm{p}_{53}$ leads to apoptosis in thyroid carcinoma cells. Cell. Mol. Life Sci. 64, 1428-1436.

Lupien, S.J., McEwen, B.S., Gunnar, M.R., Heim, C., 2009. Effects of stress throughout the lifespan on the brain, behaviour and cognition. Nat. Rev. Neurosci. 10, 434-445.

Luzio, A., Monteiro, S.M., Fontainhas-Fernandes, A.A., Pinto-Carnide, O., Matos, M., Coimbra, A.M., 2013. Copper induced upregulation of apoptosis related genes in zebrafish (Danio rerio) gill. Aquat. Toxicol. 128129, 183-189. 
Mcllwain, D.R., Berger, T., Mak, T.W., 2013. Caspase functions in cell death and disease. Cold Spring Harb. Perspect. Biol. 5, aoo8656.

Mihara, M., Erster, S., Zaika, A., Petrenko, O., Chittenden, T., Pancoska, P., Moll, U.M., 2003. P53 has a direct apoptogenic role at the mitochondria. Mol. Cell 11, 577-590.

Miller, G.W., Labut, E.M., Lebold, K.M., Floeter, A., Tanguay, R.L., Traber, M.G., 2012. Zebrafish (Danio rerio) fed vitamin E-deficient diets produce embryos with increased morphologic abnormalities and mortality. J. Nutr. Biochem. 23, 478-486.

Mounteney, J., Griffiths, P., Sedefov, R., Noor, A., Vicente, J., Simon, R., 2016. The drug situation in Europe: an overview of data available on illicit drugs and new psychoactive substances from European monitoring in 2015. Addiction 111, 34-48.

Oliveira, M.M., Teixeira, J.C., Vasconcelos-Nobrega, C., Felix, L.M., Sardao, V.A., Colaco, A.A., Oliveira, P.A., Peixoto, F.P., 2013. Mitochondrial and liver oxidative stress alterations induced by $\mathrm{N}$-butyl- $\mathrm{N}-\mathrm{C}_{4}$ hydroxybutyl)nitrosamine: relevance for hepatotoxicity. J. Appl. Toxicol. 33, 434-443.

Paglia, D.E., Valentine, W.N., 1967. Studies on the quantitative and qualitative characterization of erythrocyte glutathione peroxidase. J. Lab. Clin. Med. 70, 158-169.

Perera, F., Herbstman, J., 2011. Prenatal environmental exposures, epigenetics, and disease. Reprod. Toxicol. 31, 363-373.

Peterson, R.K., 2006. Comparing ecological risks of pesticides: the utility of a Risk Quotient ranking approach across refinements of exposure. Pest Manag. Sci. 62, 46-56.

Petrie, B., Barden, R., Kasprzyk-Hordern, B., 2015. A review on emerging contaminants in wastewaters and the environment: Current knowledge, understudied areas and recommendations for future monitoring. Water Res. 72, 3-27.

Pfaffl, M.W., 2001. A new mathematical model for relative quantification in real-time RT-PCR. Nucleic Acids Res. 29, e45.

Pias, E.K., Aw, T.Y., 2002. Early redox imbalance mediates hydroperoxide-induced apoptosis in mitotic competent undifferentiated PC-12 cells. Cell Death Differ. 9, 1007-1016.

Pikulkaew, S., Benato, F., Celeghin, A., Zucal, C., Skobo, T., Colombo, L., Dalla Valle, L., 2011. The knockdown of maternal glucocorticoid receptor mRNA alters embryo development in zebrafish. Dev. Dyn. $240,874-889$.

Pomati, F., Castiglioni, S., Zuccato, E., Fanelli, R., Vigetti, D., Rossetti, C., Calamari, D., 2006. Effects of a complex mixture of therapeutic drugs at environmental levels on human embryonic cells. Environ. Sci. Technol. 40, 2442-2447.

Reznick, A.Z., Packer, L., 1994. Oxidative damage to proteins: spectrophotometric method for carbonyl assay. Methods Enzymol. 233, 357-363. 
Richardson, S.D., Ternes, T.A., 2014. Water analysis: emerging contaminants and current issues. Anal. Chem. 86, 2813-2848.

Rinon, A., Molchadsky, A., Nathan, E., Yovel, G., Rotter, V., Sarig, R., Tzahor, E., 2011. p53 coordinates cranial neural crest cell growth and epithelial-mesenchymal transition/delamination processes. Development 138, 1827-1838.

Robinson, B.L., Dumas, M., Ali, S.F., Paule, M.G., Gu, Q., Kanungo, J., 2017. Cyclosporine exacerbates ketamine toxicity in zebrafish: Mechanistic studies on drug-drug interaction. J. Appl. Toxicol. 37, 1438-1447.

Rodayan, A., Afana, S., Segura, P.A., Sultana, T., Metcalfe, C.D., Yargeau, V., 2016. Linking drugs of abuse in wastewater to contamination of surface and drinking water. Environ. Toxicol. Chem. 35, 843-849.

Rodriguez-Fuentes, G., Rubio-Escalante, F.J., Norena-Barroso, E., Escalante-Herrera, K.S., Schlenk, D., 2015. Impacts of oxidative stress on acetylcholinesterase transcription, and activity in embryos of zebrafish (Danio rerio) following Chlorpyrifos exposure. Comp. Biochem. Physiol. C Toxicol. Pharmacol. 172-173, 1925 .

Sanden, M., Jorgensen, S., Hemre, G.I., Ornsrud, R., Sissener, N.H., 2012. Zebrafish (Danio rerio) as a model for investigating dietary toxic effects of deoxynivalenol contamination in aquaculture feeds. Food. Chem. Toxicol. 50, 4441-4448.

Santos, D., Matos, M., Coimbra, A.M., 2014. Developmental toxicity of endocrine disruptors in early life stages of zebrafish, a genetic and embryogenesis study. Neurotoxicol. Teratol. 46, 18-25.

Santos, L.H., Araujo, A.N., Fachini, A., Pena, A., Delerue-Matos, C., Montenegro, M.C., 2010. Ecotoxicological aspects related to the presence of pharmaceuticals in the aquatic environment. J. Hazard. Mater. 175, 45-95.

Schafer, F.Q., Buettner, G.R., 2001. Redox environment of the cell as viewed through the redox state of the glutathione disulfide/glutathione couple. Free Radical Bio. Med. 30, 1191-1212.

Schneider, C.A., Rasband, W.S., Eliceiri, K.W., 2012. NIH Image to ImageJ: 25 years of image analysis. Nat. Methods 9, 671-675.

Scholz, S., Fischer, S., Gundel, U., Kuster, E., Luckenbach, T., Voelker, D., 2008. The zebrafish embryo model in environmental risk assessment--applications beyond acute toxicity testing. Environ. Sci. Pollut. Res. Int. $15,394-404$.

Schuler, M., Bossy-Wetzel, E., Goldstein, J.C., Fitzgerald, P., Green, D.R., 2000. P53 induces apoptosis by caspase activation through mitochondrial cytochrome c release. J. Biol. Chem. 275, 7337-7342.

Seok, S.H., Baek, M.W., Lee, H.Y., Kim, D.J., Na, Y.R., Noh, K.J., Park, S.H., Lee, H.K., Lee, B.H., Park, J.H., 2008. In vivo alternative testing with zebrafish in ecotoxicology. J. Vet. Sci. 9, 351-357.

Shi, Y., 2002. Mechanisms of caspase activation and inhibition during apoptosis. Mol. Cell 9, 459-470. 
Shi, Y., 2004. Caspase activation, inhibition, and reactivation: a mechanistic view. Protein Sci. 13, 1979-1987.

Slaninova, A., Smutna, M., Modra, H., Svobodova, Z., 2009. A review: oxidative stress in fish induced by pesticides. Neuro Endocrinol. Lett. 30 Suppl 1, 2-12.

Soares, J., Coimbra, A.M., Reis-Henriques, M.A., Monteiro, N.M., Vieira, M.N., Oliveira, J.M., Guedes-Dias, P., Fontainhas-Fernandes, A., Parra, S.S., Carvalho, A.P., Castro, L.F., Santos, M.M., 2009. Disruption of zebrafish (Danio rerio) embryonic development after full life-cycle parental exposure to low levels of ethinylestradiol. Aquat. Toxicol. 95, 330-338.

Stackley, K.D., Beeson, C.C., Rahn, J.J., Chan, S.S., 2011. Bioenergetic profiling of zebrafish embryonic development. PLoS ONE 6, e25652.

Sui, Q., Cao, X., Lu, S., Zhao, W., Qiu, Z., Yu, G., 2015. Occurrence, sources and fate of pharmaceuticals and personal care products in the groundwater: A review. Emerging Contaminants 1, 14-24.

Tedeschi, A., Di Giovanni, S., 2009. The non-apoptotic role of p53 in neuronal biology: enlightening the dark side of the moon. EMBO Rep. 10, 576-583.

Tennekes, H.A., 2017. Dose: Time-to-effect analyses can identify hazardous chemicals at an early stage of product development. Environ. Risk Assess. Remediat. 1, 16-21.

Toth, A.B., Shum, A.K., Prakriya, M., 2016. Regulation of neurogenesis by calcium signaling. Cell Calcium $59,124-134$.

Usenko, C.Y., Hopkins, D.C., Trumble, S.J., Bruce, E.D., 2012. Hydroxylated PBDEs induce developmental arrest in zebrafish. Toxicol. Appl. Pharmacol. 262, 43-51.

Varga, Z.M., 2011. Aquaculture and husbandry at the zebrafish international resource center. Methods Cell Biol. 104, 453-478.

Venancio, C., Felix, L., Almeida, V., Coutinho, J., Antunes, L., Peixoto, F., Summavielle, T., 2015. Acute ketamine impairs mitochondrial function and promotes superoxide dismutase activity in the rat brain. Anesth. Analg. 120, 320-328.

Wang, X.H., Lin, A.Y., 2014. Is the phototransformation of pharmaceuticals a natural purification process that decreases ecological and human health risks? Environ. Pollut. 186, 203-215.

West, A.E., Chen, W.G., Dalva, M.B., Dolmetsch, R.E., Kornhauser, J.M., Shaywitz, A.J., Takasu, M.A., Tao, X., Greenberg, M.E., 2001. Calcium regulation of neuronal gene expression. Proc. Natl. Acad. Sci. U. S. A. $98,11024-11031$.

Westerfield, M., 2007. The zebrafish book: a guide for the laboratory use of zebrafish (Danio rerio), 5 th ed. University of Oregon press. 
Xu, T., Zhao, J., Hu, P., Dong, Z., Li, J., Zhang, H., Yin, D., Zhao, Q., 2014. Pentachlorophenol exposure causes Warburg-like effects in zebrafish embryos at gastrulation stage. Toxicol. Appl. Pharmacol. 277, 183191.

Xu, T., Zhao, J., Xu, Z., Pan, R., Yin, D., 2016. The developmental effects of pentachlorophenol on zebrafish embryos during segmentation: A systematic view. Sci Rep 6, 25929.

Yan, J., Huang, Y., Lu, Y., Chen, J., Jiang, H., 2014. Repeated administration of ketamine can induce hippocampal neurodegeneration and long-term cognitive impairment via the ROS/HIF-1A pathway in developing rats. Cell. Physiol. Biochem. 33, 1715-1732.

Yang, X., Klein, R., Tian, X., Cheng, H.T., Kopan, R., Shen, J., 2004. Notch activation induces apoptosis in neural progenitor cells through a p53-dependent pathway. Dev. Biol. 269, 81-94.

Zhu, L., Mu, X., Wang, K., Chai, T., Yang, Y., Qiu, L., Wang, C., 2015. Cyhalofop-butyl has the potential to induce developmental toxicity, oxidative stress and apoptosis in early life stage of zebrafish (Danio rerio). Environ. Pollut. 203, 40-49.

Zuccato, E., Castiglioni, S., 2009. Illicit drugs in the environment. Philos. Trans. A Math. Phys. Eng. Sci. 367 , 3965-3978.

Zurlo, J., 2012. No animals harmed: toward a paradigm shift in toxicity testing. Hastings Cent. Rep. Suppl, S23-26. 